ra là khá nhỏ.

+ Đánh giá NYHA sau mổ thời điểm xuất viện có đến 92,1\% NYHA I, có sự cải thiện rõ rệt khi trước mổ là 98,7\% NYHA II và III.

+ Vấn đề điêuu chỉnh thuốc chống đông cho bệnh nhân trước khi ra viện cũng rất được quan tâm với chỉ số INR là $2,81 \pm 0,64$ với liều Sintrom trung bình là $1,48 \pm 0,35 \mathrm{mg}$.

\section{KẾT LUÂ̂N}

Hẹp van hai lá là bệnh tim phổ biến, có nhiêu biến chứng nguy hiểm.Thay van hai lá cơ học ATS Open Pivot là phương pháp điêu trị tốt cho phân lớn bệnh nhân bị hẹp van hai lá. Sau mổ, tỷ lệ biến chứng thấp, tình trạng tăng áp lực động mạch phổi và suy tim cải thiện đáng kể theo thời gian. Hơn nữa với ưu điểm tiếng van nhỏ và giá thành thấp, van ATS Open Pivot sẽ làm tăng chất lượng sống cho bệnh nhân sau mổ.

\section{TÀI LIẸU THAM KHẢO}

1. Nguyễn Lân Viêt (2003). Thức hành bênh tim mạch, Nhà xuất bản Y học Hà Nội, tr.219 - 266.

2. Bonow RO., Carabello B., Leon A.C. Jr. (1998). ACC/AHA guidelines for the management of patients with valvular heart disease: a report of the American College of Cardiology/American Heart Association Task Force on Practice Guidelines (Committee on Management of Patients With Valvular Heart Disease). Journal of American College of Cardiology, 32 (5), pp. $1486-1588$.

3. Butchart EG (2001). Twenty years' experience with the Metronic Hall Valve.J Thorac Cardiovasc Surg 2001, pp.1090-1100.

4.Yuichiro Kaminishi (2009). The ATS bileaflet prothetic heart valve. Mid-term result from single center. Journal of American College of Cardiology, 30, pp. 1230-1238.

5. Nguyến Đức Hiền, Bùi Đức Phú(2007). Đánh giá kết quả phấu thuât thay van hai lá cơ hoc ơ bênh nhân hẹp van hai lá. Tap chí tim mạch học thành phố Hồ Chí Minh số 11 năm 2007.

6. Đăng Hanh Sơn (2010). Nghiên cứu đánh giá kểt quả phẩu thuật thay van hai lá bằng van cơ học Sorin tại Bênh viên Tim Hà Nội. Luận án Tiến sĩ y học, Học viện Quẩn y.

7. Đoàn Quốc Hửng, Nguyễn Duy Thắng (2012) Nghiên cứu đặc điểm lâm sàng, cận lâm sàng và kết quả thay van cơ học tại Bệnh viện hữu nghị Việt Đức. Tạp chí Tim mạch học Việt Nam, số 61, $\operatorname{tr}$ 21-32.

8. Đố Xuâ̂n Hai (2019). Nghiên cứu đánh giá kết quả phẩu thuật thay van hai lá bằng van cơ học St.Jude tại Bệnh viện Trung ương Quân đội 108. Luận án tiến sĩ y học, Học viện Quân y.

\title{
KẾT QUẢ ĐÎ̂̀U TRI CHẤN THƯƠNG SỌ NÃO Ở NGƯỜI CAO TUỔI TẠI BỆNH VIỆN ĐA KHOA TỈNH THÁI BÌNH
}

\section{TÓM TẮT}

Mục tiêu: Nhận xét lâm sàng, tổn thương trên chụp cắt lớp vi tính và kết quả điêu trị chấn thương sọ não ở người cao tuổi. Phương pháp: Mô tả cắt ngang 161 bệnh nhân cao tuổi bị chấn thương sọ não điêu trị tại bệnh viện Đa khoa tỉnh Thái Bình trong thời gian từ tháng 2 đến tháng 8 năm 2020. Kết quả: $161 / 534$ bệnh nhân chiếm tỉ lề $(30,1 \%)$ gồm 101 nam $(62,7 \%), 60$ nữ $(37,3 \%)$; tuổi trung bình $71,1 \pm 8,8$; nguyên nhân tai nạn giao thông $51,6 \%$, tai nạn sinh hoat $42,8 \%$. Lâm sàng mức độ nhẹ chiếm đa số $(91,3 \%)$, mức độ trung bình $(6,2 \%)$, chỉ có $(2,5 \%)$ mức độ năng. Tổn thương trên phim cắt lớp vi tính: Máu tự dưới màng cứng cấp tính chiếm tỉ lệ cao nhất $(47,2 \%)$, chảy máu màng mềm $(28,6 \%)$, máu tụ ngoài màng cứng $(5,6 \%)$. Có 14 bệnh lý mạn tính được ghi nhân trong tổng số 161 bệnh nhân nhâp viện. Trong đó gặp nhiều nhất là tăng huyết áp $(24,2 \%)$, tiểu đường typ 2 gặp $(9,9 \%)$. Điều trị nội

*Trường Đại họ Y Dược Thái Bình

Chịu trách nhiệm chính: Vũ Minh Hải

Email: vuminhhai777@gmail.com

Ngày nhận bài: 5.4.2021

Ngày phản biên khoa hoc: 24.5.2021

Ngày duyệt bài: 3.6.2021
Vũ Minh Hải*

khoa chiếm đa số $(86,3 \%)$, chỉ có $(13,7 \%)$ phẫu thuât. Tình trang ra viên ổn định $90,7 \%$; di chứng nhe $4,3 \%$, di chứng chứng vừa $2,5 \%$, di chứng nặng 1,9\%. Tử vong $0,6 \%$. Kết luân: Chấn thương sọ não người cao tuối, nam giới chiếm tỉ lệ cao. Bệnh mạn tính đi kèm găp nhiều nhất là tiểu đường; Loại máu tu thường gặp là dưới màng cứng cấp tính $(47,2 \%)$, phẫu thuật chiếm $(13,7 \%)$. Kết quả ra viện ổn định chiếm $(90,7 \%)$. Tử vong $(0,6 \%)$.

Tư' khóa: chấn thương sọ não người cao tuổi; chấn thương sọ não

\section{SUMMARY \\ OUTCOMES OF GERIATRIC TRAUMATIC BRAIN INJURIES TREATMENT AT THAI BINH GENERAL HOSPITAL}

Objectives: To assess clinical characteristics, lesions on CT scan and treatment outcomes of traumatic brain injury in the elderly. Methods: Crosssectional descriptive study carried out among 161 elderly patients with traumatic brain injury treated at Thai Binh Provincial General Hospital during the period from February to August 2020. Results: 161/534 patients equalled $(30.1 \%)$, including 101 males $(62.7 \%), 60$ females $(37.3 \%) ;$ median age $71.1 \pm 8.8$; the most comme cause was traffic accidents which 
accounted for $51.6 \%$, domestic accidents made up $42.8 \%$. Clinical severity comprised minor (91.3\%), moderate $(6.2 \%)$, severe $(2.5 \%)$ only. CT findings: Acute subdural hematoma accounted for the highest rate $(47.2 \%)$, the following were subarachnoid hemorrhage $(28.6 \%)$ and epidural hematoma (5.6\%). There were 14 cases having chronic diseases out of 161 hospitalized patients. In which, the most common was hypertension (24.2\%), type 2 diabetes $(9.9 \%)$. Conservative treatment accounted for the majority $(86.3 \%)$, only $(13.7 \%)$ underwent surgery. Hospital discharge state: stable $90.7 \%$; mild sequelae $4.3 \%$, moderate sequelae $2.5 \%$, severe sequelae $1.9 \%$. Mortality $0.6 \%$. Conclusion: In geriatric traumatic brain injuries, males accounted for a high rate. The most common chronic comorbidity was diabetes; The most common type of hematoma was acute subdural (47.2\%), surgeries accounted for $(13.7 \%)$. The stability on hospital discharge achieved (90.7\%). Mortality (0.6\%).

Keyword: traumatic brain injury in the elderly; traumatic brain injury.

\section{I. ĐẶT VẤN ĐỀ}

Chấn thương so não là môt cấp cứu ngoại khoa thường gặp. Điều trị chẩn thương sọ não vẫn là một thách thức đối với chuyên ngành hồi sức tích cực và ngoại thần kinh, đặc biệt là đối tượng người cao tuổi. Người cao tuổi khi bị chấn thương sọ não gặp nhiều khó khăn hơn vì ngoài việc xử trí các thương tổn do chấn thương gây ra các thầy thuốc còn cần phải lưu ý đến các đặc điểm riêng ở người cao tuổi như điều trị các bệnh phối hợp các bệnh mạn tính như tim mạch, tiểu đường, tăng huyết áp... Chúng tôi báo cáo 161 trường hợp người cao tuổi bị chấn thương so não điều trị tại bệnh viện Đa khoa tỉnh Thái Bình nhằm mục đích nâng cao kết quả điều trị nhóm đối tượng này.

\section{II. ĐỐI TƯợNG VÀ PHƯƠNG PHÁP NGHIÊN CỨU}

2.1. Địa bàn nghiên cứu. Bệnh viện Đa khoa tỉnh Thái Bình.

2.2. Đối tượng nghiên cứu. 161 bệnh nhân cao tuổi, chấn thương sọ não điều trị tại khoa Phẫu thuật Thần kinh-Cột sống, bệnh viện Đa khoa tỉnh Thái Bình trong thời gian từ tháng 2 đến tháng 8 năm 2020.

2.3. Phương pháp nghiên cứu. Mô tả cắt ngang lâm sàng, chẩn đoán hình ảnh và thái độ xử trí.

\section{KẾT QUẢ NGHIÊN CỨU}

Bảng 3.1 Phân bố theo nhóm tuổi, giới

\begin{tabular}{|c|c|c|c|c|}
\hline Giới & \multicolumn{2}{|c|}{ Nam } & \multicolumn{2}{|c|}{ Nữ } \\
\cline { 2 - 5 } Nhóm tuổi & $\mathbf{n}$ & $\mathbf{\%}$ & $\mathbf{n}$ & $\mathbf{\%}$ \\
\hline $60-69$ & 57 & 70,4 & 24 & 29,6 \\
\hline $70-79$ & 28 & 62,2 & 17 & 37,8 \\
\hline
\end{tabular}

\begin{tabular}{|c|c|c|c|c|}
\hline$\geq 80$ & 16 & 45,7 & 19 & 54,3 \\
\hline Tống & $\mathbf{1 0 1}$ & $\mathbf{6 2 , 7}$ & $\mathbf{6 0}$ & $\mathbf{3 7 , 3}$ \\
\hline Nhận xét: Độ tuổi $60-69$ chiếm tỉ lệ cao nhất \\
\hline
\end{tabular}
$(50,3 \%)$, tuổi 70 -79 chiếm $(27,9 \%)$, trên 80 tuối $(21,8 \%)$. Tuổi trung bình $71,1 \pm 8,8$, thấp nhất 60 tuổi, cao tuổi nhất 96 . Nam chiếm $62,7 \%$, nữ chiếm 37,3\%.

Bảng 3.2 Nguyên nhân chấn thương

\begin{tabular}{|c|c|c|c|}
\hline Nguyên nhân & $\mathbf{n}$ & $\begin{array}{c}\text { Tỷ lệ } \\
\mathbf{\%}\end{array}$ & $\begin{array}{c}\text { Tổng } \\
\mathbf{\%}\end{array}$ \\
\hline Tai nạn giao thông & 83 & 51,6 & \multirow{2}{*}{98,1} \\
\hline Tai nạn lao động & 6 & 3,7 & \multirow{2}{*}{9} \\
\hline Tai nạn sinh hoạt & 69 & 42,8 & \\
\hline Bạo lực & 3 & 1,9 & 1,9 \\
\hline Tống & $\mathbf{1 6 1}$ & $\mathbf{1 0 0}$ & $\mathbf{1 0 0}$ \\
\hline
\end{tabular}

Nhận xét: Tai nạn giao thông chiếm $51,6 \%$, tai nạn sinh hoạt $42,8 \%$.

Bảng 3.3 Các triệu chứng lâm sàng

\begin{tabular}{|c|c|c|c|}
\hline & Triệu chứng & $\mathbf{n}$ & Tỷ lệ \\
\hline \multirow{9}{*}{$\begin{array}{c}\text { Triệu } \\
\text { chứng } \\
\text { lâm sàng }\end{array}$} & Hôn mê & 7 & 4,3 \\
\hline & Đau đâu & 141 & 87,6 \\
\hline & Nôn & 30 & 18,6 \\
\hline & Chảy máu mũi & 4 & 2,5 \\
\hline & Chảy máu tai & 8 & 5,0 \\
\hline & Bầm tím quanh mắt & 16 & 9,9 \\
\hline & Tụ máu dưới da đầu & 41 & 25,5 \\
\hline & Vết thương vùng đầu & 47 & 29,2 \\
\hline & Khác & 31 & 19,3 \\
\hline \multirow{3}{*}{$\begin{array}{c}\text { Dấu hiệu } \\
\text { thần kinh } \\
\text { khu trú }\end{array}$} & Liệt $1 / 2$ người & 16 & 9,9 \\
\hline & Liệt dây VII & 1 & 0,6 \\
\hline & Giãn đồng tử 1 bên & 1 & 0,6 \\
\hline
\end{tabular}

Nhân xét: Triêu chứng đau đầu chiếm $87,6 \%$; tụ máu dưới da đầu $25,5 \%$; liệt nửa người $9,9 \%$.

Bảng 3.4 Mức độ nặng theo tri giác

\begin{tabular}{|c|c|c|}
\hline Mức độ tri giác theo GCS & $\mathbf{n}$ & Tỷ lệ \% \\
\hline $13-15$ điểm & $\mathbf{1 4 7}$ & $\mathbf{9 1 , 3}$ \\
\hline 9-12 điếm & 10 & 6,2 \\
\hline 3-8 điểm & 4 & 2,5 \\
\hline Tống & $\mathbf{1 6 1}$ & $\mathbf{1 0 0}$ \\
\hline
\end{tabular}

Nhận xét: Mức độ nhẹ chiếm đa số $(91,3 \%)$, mức độ trung bình $(6,2 \%)$, chỉ có (2,5\%) mức độ nẳng.

Bảng 3.5 Tổn thương trên chụp cắt lớp
vi tính
\begin{tabular}{|c|c|c|}
\hline Loại máu tụ & $\mathbf{n}$ & Tỷ lệ \% \\
\hline Máu tụ ngoài màng cứng & 9 & 5,6 \\
\hline Máu tụ dưới màng cứng cấp tính & $\mathbf{7 6}$ & $\mathbf{4 7 , 2}$ \\
\hline Máu tụ trong não & 16 & 9,9 \\
\hline Chảy máu màng mềm & 46 & 28,6 \\
\hline Phù não nằng & 3 & 1,9 \\
\hline 2 loại tốn thương & 21 & 13,0 \\
\hline 3 loại tốn thương & 5 & 3,1 \\
\hline
\end{tabular}


Nhân xét: Máu tụ dưới màng cứng cấp tính chiếm tỉ lệ cao nhất $(47,2 \%)$, chảy máu màng mềm $(28,6 \%)$, máu tụ ngoài màng cứng $(5,6 \%)$.

Bảng 3.6 Các bềnh lý man tính kèm theo

\begin{tabular}{|c|c|c|}
\hline Bệnh lý mạn tính kèm theo & $\mathbf{n}$ & $\begin{array}{c}\text { Tỷ lệ } \\
\text { \% }\end{array}$ \\
\hline Suy tim & 6 & 37 \\
\hline Tai biến mạch máu não 1 lần & 8 & 5,0 \\
\hline Liệt nửa người do tai biến & 2 & 1,2 \\
\hline len suyến, phối tắc nghẽn mạn tính & 5 & 3,1 \\
\hline thón dur̀ & 16 & 9,9 \\
\hline Bệnh thận & 6 & 3,7 \\
\hline Bệnh gan mạn tí & 9 & 5,6 \\
\hline Viêm/loét c & 10 & 6,2 \\
\hline $\operatorname{lng}$ & 2 & 1,2 \\
\hline Alzh & 2 & 1,2 \\
\hline Thấp khớp & 3 & 1,9 \\
\hline Tăng I & 39 & 24,2 \\
\hline & 1 & 0,6 \\
\hline Sử dụng thuốc chống đôn & 1 & 0,6 \\
\hline
\end{tabular}

Nhận xét: Có 14 bệnh lý mạn tính được ghi nhân trong tổng số 161 bệnh nhân nhập viện. Trong đó găp nhiêu nhất là tăng huyết áp (24,2\%), tiểu đường typ 2 gặp (9,9\%).

Bảng 3.7 Thái độ xử trí

\begin{tabular}{|c|c|c|}
\hline & $\mathbf{n}$ & Tỷ lệ $\%$ \\
\hline Nội khoa & $\mathbf{1 3 9}$ & $\mathbf{8 6 , 3}$ \\
\hline Phầu thuậ̂t & 22 & 13,7 \\
\hline Tống số & $\mathbf{1 6 1}$ & $\mathbf{1 0 0}$ \\
\hline
\end{tabular}

Nhận xét: Điều trị nội khoa chiếm đa số $(86,3 \%)$, chỉ có $(13,7 \%)$ phẫu thuật.

Bảng 3.8 Tình trạng tri giác khi ra viện

\begin{tabular}{|c|c|c|}
\hline Kết quả điều trị & $\mathbf{n}$ & Tỷ lệ \% \\
\hline Tốt (GCS 14-15đ) & 146 & 90,7 \\
\hline Khá (GCS 12-13đ) & 7 & 4,3 \\
\hline Trung bình (GCS 9-11đ) & 4 & 2,5 \\
\hline Kém (GCS 3-8đ) & 3 & 1,9 \\
\hline Tứ vong & 1 & 0,6 \\
\hline Tống & $\mathbf{1 6 1}$ & $\mathbf{1 0 0}$ \\
\hline
\end{tabular}

Nhận xét: Tình trạng ra viện ốn định 90,7\%; di chứng nhẹ 4,3\%, di chứng trung bình 2,5\%, di chứng nặng 1,9\%. Tứ vong $0,6 \%$.

\section{BÀN LUÂN}

4.1. Tỉ lệ, tuổi, giới. Chấn thương sọ não người cao tuổi chiếm tỉ lệ 30,1\% (161/534) bệnh nhân chấn thương sọ não điêu trị trong thời gian 8 tháng, từ tháng 2 đến tháng 9 năm 2020 tại khoa Phẫu thuật thần kinh cột sống bệnh viện Đa khoa tỉnh Thái Bình.

Tuổi trung bình trong nghiên cứu của chúng tôi là $71,1 \pm 8,8$ tuổi, thấp nhất 60 tuổi, cao tuổi nhất 96. Đô tuổi 60-69 chiếm tỉ lê cao nhất (50,3\%), tuổi $70-79$ chiếm $(27,9 \%)$, trên 80 tuổi $(21,8 \%)$. Độ tuổi nghiên cứu của chúng tôi tương đương với tác giả Đàm Quang Thịnh (2014) báo cáo từ tháng $1 / 2014$ đến hết tháng 6/2014 tại Khoa Phẫu thuật Thần kinh Bệnh viện Viêt Đức có 97 bênh nhân có tuổi từ 60 trở lển được chẩn đoán là chấn thương so não. Trong đó độ tuổi từ 60 - 69 đông nhất là $54(55,7 \%)$ bệnh nhân cao tuổi nhất là 96 , tuổi trung bình là 70,7 . Theo đô tuổi từ $80-60$ chiếm tỳ lê cao $83,5 \%$. Trên 80 tuổi chiếm 16,5\%. Kết quả này phù hợp với một thực tế đó là tuổi thọ trung bình của người Việt Nam hiện nay là 73.

Giới: nam chiểm $62,7 \%$, nữ chiếm $37,3 \%$, tỉ lệ nam/nữ của chúng tôi là 1,68 . Tỉ lệ này gần tương đương với Đàm Quang Thịnh (2014) là 1,9[1] và Phạm Ty. (2010) báo cáo 177 trường hợp chấn thươnng sọ não ở người cao tuổi, tỉ lệ nam $(68,9 \%)$, nữ $(31,1 \%)$ [2].

Nguyên nhân chấn thương sọ não nhóm bệnh nhân của chúng tôi do tai nạn giao thông chiếm $51,6 \%$, tai nạn sinh hoạt $42,8 \%$. Đàm Quang Thịnh (2014), bệnh nhân chấn thương do tai nạn giao thông là $(61,9 \%)$, do ngã $27,8 \%$. Chúng tôi ghi nhân $43,8 \%$ nguyên nhân là do ngã, điều này cũng phù hợp với đặc điểm của người cao tuổi, tuy nhiên cao hơn tác giả Đàm Quang Thịnh nhưng thấp hơn báo cáo của Lara $A$ Harvey, Jacqueline C.T. Close (2013) có12.564 trường hợp nhập viện vì chấn thương sọ não trong suốt 13 năm nghiên cứu thấy té ngã là nguyên nhân phổ biến nhất của chấn thương sọ não (82,9\%). Phần lớn các cú ngã là do ngã ở cùng một mức độ và xảy ra ở nhà [3].

4.2. Lâm sàng và chẩn đoán hình ảnh. Tình trạng lâm sàng của 161 bệnh nhân của chúng tôi thây: mức độ nhẹ chiếm đa số $(91,3 \%)$, mức độ trung bình $(6,2 \%)$, chỉ có (2,5\%) mức độ nặng. Theo Đàm Quang Thịnh (2014), mức độ nhẹ chiếm (63,9\%) [1].

Tôn thương trên phim chụp cắt lớp vi tính 161 bênh nhân thấy: Máu tụ dưới màng cứng cấp tính chiếm tỉ lệ cao nhất $(47,2 \%)$, chảy máu màng mềm $(28,6 \%)$, máu tụ ngoài màng cứng $(5,6 \%)$. Lara A Harvey, Jacqueline C.T. Close (2013) nhận xét máu tụ dưới màng cứng do chấn thương $(42,9 \%)$, dập não $(24,1 \%)$ và xuất huyết dưới nhện do chấn thương $(12,7 \%)$ là loại chấn thương phổ biến nhất [3]. Tác giả Đàm Quang Hưng (2014) cho biết tî lệ máu tụ dưới màng cứng cấp tính là $61,9 \%$ [1]. Điều này phù hợp với đặc điểm giải phấu, bệnh lý trong chấn thương sọ não ở người cao tuổi khi màng cứng dính chặt vào hộp sọ, thành mạch dễ tổn thương, khi thể tích não giảm đi trong khi đó thể tích hộp sọ không đổi dẩn đến có nhiều khoảng 
trống giữa hộp sọ và não bởi vậy có thể giải thích được tại sao có nhiều bệnh nhân vào viện vẫn tỉnh táo (Glasgow từ 13 - 15điểm) nhưng khi kiểm tra trên phim cắt lớp vi tính ta thấy có máu tụ dưới màng cứng.

4.3. Kết quả điêu trị. Chúng tôi điều trị nội khoa cho đa số bệnh nhân $(86,3 \%)$, chỉ có $(13,7 \%)$ có chỉ định phẫu thuật. Tình trạng ra viện ổn định $90,7 \%$; di chứng nhẹ 4,3\%, di chứng trung bình $2,5 \%$, di chứng nặng $1,9 \%$. Tư vong 0,6\%. Đàm Quang Hưng báo cáo 97 bệnh nhân, có 77 trường hợp $(79,3 \%)$ điều trị nội khoa, kết quả tốt $81,8 \%$, trung bình $13 \%$, xấu $5,2 \%$. Nhóm phẫu thuật tốt $85 \%$, trung bình $10 \%$, xấu $5 \%$ [1].

\section{KẾT LUÂN}

Chấn thương sọ não người cao tuổi, nam giới chiếm tỉ lệ cao. Bệnh mạn tính đi kèm gặp nhiều nhất là tiểu đường; Loại máu tụ thường gặp là dưới màng cứng cấp tính $(47,2 \%)$, phẩu thuật chiếm $(13,7 \%)$. Kết quả ra viện ổn định chiếm $(90,7 \%)$. Tử vong $(0,6 \%)$.

\section{TÀI LIỆ THAM KHẢO}

1. Đàm Quang Thịnh (2014), "Nghiên cứu đặc điểm lầm sàng, chẩn đoán hình ảnh và kết quả điêu tri chẩn thương so não cấp tính ở người cao tuổi", luận văn tốt nghiệp bác sĩ chuyên khoa 2, trường Đai hoc Y Hà Nôi, năm 2014.

2. Phạm Ty. (2010), " Chẩn thương sọ não không có chỉ định phẫu thuật ở người cao tuổi ', tạp chí Y học Việt Nam, tháng 5, số 1/2010.

3. Lara A Harvey, Jacqueline C.T. Close (2013). Traumatic brain injury in older adults: Characteristics, causes and consequences. Injury, Volume 44, Issue 2, 277.

\section{HIÊUU QUẢ CỦA KHỞI PHÁT CHUYỂN DẠ BẰNG ỐNG THÔNG FOLEY ĐĂT Ơं KÊNH CỔ TỬ CUNG Ở THAI TRÊN 40 TUẦ TAI BÊ̂NH VIỆN TỪ DỨ}

\section{TÓM TẮT}

Đăt vấn đề: Trong các phương pháp khởi phát chuyển dạ, đặt ống thông Foley ở kênh cổ tử cung là một phương pháp đơn giản, chi phí thấp, được áp dụng phổ biến tai các bệnh viện lớn ở Việt Nam. Việc lựa chọn thời điểm chấm dứt thai kỳ phù hợp vừa cho hiệu quả thành công cao, vừa hạn chế được tử suất và bênh suất cho me và thai nhi ngày càng được quan tâm [7]. Mục tiêu: Xác định tỉ lệ khởi phát chuyển dạ thành công của ống thông Foley đặt kênh cổ tử cung ở thai phụ trên 40 tuân chưa vào chuyển dạ tại Bệnh viên Tữ Dũ. Phương pháp: Nghiên cứu mô tả loạt ca tiến cứu trên 385 sản phụ tuổi thai trên 40 tuân chưa vào chuyển dạ tại Bệnh viện Từ Dũ từ tháng 11/2020 đến tháng 4/2021. Kết quả: Tỉ lệ khởi phát chuyển dạ thành công bằng thông Foley đặt ở kênh cổ tử cung là 83,11\% [95\%CI: 79,35-86,87]. Yếu tố thông Foley tự rớt/ rút liên quan đến sự thành công của khởi phát chuyển dạ $\mathrm{PR}=0,51$ [95\%CI: 0,29-0,91]. Tỉ lệ sinh ngả âm đạo sau khởi phát chuyến dạ là 44,94\% với các yếu tố liên quan là yếu tố tiền thai, yếu tố tiền căn mổ lấy thai và yếu tố kết quả khởi phát chuyển dạ. Kết luận: Tỉ lệ khởi phát chuyển thành công bằng ống thông Foley đặt ở kênh cổ tử cung là 83,11\%. Đây là phương pháp khởi phát chuyển dạ cho hiệu

\footnotetext{
${ }^{1}$ Đại học Y Dược TP.HCM

${ }^{2}$ Bềnh viện Tữ Dũ

Chịu trách nhiệm chính: Võ Minh Tuấn

Email: vominhtuan@ump.edu.vn

Ngày nhận bài: 5.4.2021

Ngày phản biên khoa học: 24.5.2021

Ngày duyệt bài: 2.6 .2021
}

quả thành công cao, giúp tăng khả năng sinh ngả âm đạo và tỉ lệ biến chứng thấp, không nguy hiểm, có thể theo dõi và can thiêp kip thời.

Tư khóa: Khởi phát chuyển dạ, Ống thông Foley, Thai trên 40 tuần.

\section{SUMMARY \\ EFFICIENCY OF TRANSCERVICAL FOLEY CATHETER WITHIN CERVICAL CANAL FOR INDUCTION OF LABOR ON WOMEN BEYOND 40 WEEKS GESTATION AT TU DU HOSPITAL}

Background: Foley catheter as an induction agent has already been shown as a clinically effective, simple, and low-cost method, and widely used in Vietnam. The decision about the right time to indicate labor induction, which not only is effective but also reduces marternal and fetal mortality and morbidity rate, is increasingly concerned. Objective: To identify the labor induction success rate on women beyond 40 weeks gestation indicated transcervical Foley catheter at Tu Du Hospital. Methods: The study reported on series of 385 pregnant women beyond 40 gestational weeks before the spontaneous onset of labor, conducted between November 2020 and April 2021 at Tu Du Hospital. Results: The rate of labor induction success accounts for $83.11 \%$ [95\%CI: 79.35-86.87]. The balloon self-fall/ deflated factor is associated with successful rate PR $=0.51$ [95\%CI: 0.29-0.91]. The vaginal delivery rate is $44.94 \%$ with 3 relative factors: nulliparous or multiparous factor, history of Cesarean delivery factor and efficiency of Foley labor induction factor. Conclusions: The rate of labor induction success accounts for $83.11 \%$. This is a highly successful labor induction method, helping to increase 